\title{
Case Series of Safety of BCL2 and IDH Inhibition Combination for Myeloid Leukemia
}

\author{
Mavinahally $T^{*}$, Hennig $T$ and Rizzieri D \\ Division of Hematologic Malignancies and Cellular Therapy, Duke Cancer Institute, USA
}

\begin{abstract}
The incidence rate of leukemia was $13.8 \%$ between 2011 to 2015 and the death rate was $6.5 \%$ between 2012 to 2016. The data shows that the death rate was almost half of the incidence and need for newer therapies to treat leukemia. Acute myeloid leukemia is characterized by rapid growth of myeloid lineage cells in the bone marrow and appearance of blasts in peripheral blood. The mainstay of treatment is chemotherapy and sometimes given with targeted drug therapy. Targeted drugs work differently compared to standard chemotherapy and when used individually for treatment has given encouraging results. We report a case series of three patients treated at our center for relapsed AML with $I D H$ inhibitor and $B C L-2$ inhibitor combination for more than 2 months and attained morphological leukemia free state and cytopenia.
\end{abstract}

\section{Introduction}

Acute Myeloid Leukemia (AML) is a malignant disorder of hemopoietic stem cells characterized by clonal expansion of abnormally differentiated blasts of myeloid lineage [1]. With the development of methodologies of large scale sequencing, new genetic mutations associated with AML have been identified, offering new opportunities for therapy [2]. Recent discoveries have highlighted an important role of dysregulated epigenetic mechanisms in the pathogenesis of the disease [3]. Current agents that affect epigenetic are the DNA methyltransferase inhibitors, azacitidine and decitabine and both drugs have activity against AML [4].

Additionally, various novel agents targeting molecular pathway abnormalities have demonstrated clinical activity, either as single agents (e.g. Isocitrate Dehydrogenase (IDH)

\section{OPEN ACCESS}

*Correspondence:

Tanushri Mahesh Mavinahally, Division

of Hematologic Malignancies and

Cellular Therapy, Duke Cancer Institute,

2400 Pratt Street, Durham, NC 27705,

USA, Tel: +91-9008278726;

E-mail: tanu_0925@ymail.com

Received Date: 20 Jan 2020

Accepted Date: 17 Feb 2020

Published Date: 25 Feb 2020

Citation:

Mahesh MT, Hennig T, Rizzieri D.

Case Series of Safety of BCL2 and IDH Inhibition Combination for Myeloid Leukemia. Am J Leuk Res. 2020; 4(1):

1019.

Copyright $\odot 2020$ Mahesh MT. This is an open access article distributed under

the Creative Commons Attribution

License, which permits unrestricted

use, distribution, and reproduction in any medium, provided the original work is properly cited. inhibitors or BCL-2 inhibitors) or in combination with standard therapy at diagnosis or in salvage [5]. IDH inhibitors such as enasidenib (IDH2 inhibitor) and ivosidenib (IDH1 inhibitor) as well as $B C L-2$ inhibitor venetoclax have been approved by FDA for treatment of AML [6-8]. Responses are very encouraging, though cure still not achieved, thus prompting interest in novel combinations. These studies are ongoing and we support their completion and eagerly await their conclusions, however current patients and physicians need guidance on combinations that may be tried in the interim. Thus, we report a case series of three sequentially treated patients treated at our center for relapsed AML with $I D H$ and $B C L-2$ inhibitor combination. This retrospective review was approved by our local IRB. Electronic medical records were reviewed for response, safety, and toxicity of the combination (Table 1).

\section{Case Series}

\section{Case 1}

The first patient is 63 years of age with secondary AML and received standard ' $7+3$ ' induction for secondary AML with multiple molecular abnormalities including IDH1 and IDH2 abnormalities. He had progression within 2 weeks and thus was given decitabine $20 \mathrm{mg} / \mathrm{m}^{2}$ for 10 days a month and enasidenib $100 \mathrm{mg}$ daily. The patient achieved a short lasting hematologic remission with a bone marrow biopsy performed at 3 months due to worsening counts confirming progression. Venetoclax $400 \mathrm{mg}$ daily was added to the current doublet regimen. Dose reduction was not necessary as he was not on any antifungal drugs. The patient received 2 cycles of this triplet over 2 months which resulted in a morphologic leukemia Free State and negative molecular next generation sequence result. He is currently early post allogeneic transplantation with successful engraftment and remission continues.

\section{Case 2}

The second patient is a 68 years of age with secondary leukemia arising from CMML. He received decitabine based therapy in combination with other phase 1 study agents, deriving a morphologic 
Table 1: Electronic medical records were reviewed for response, safety, and toxicity of the combination.

\begin{tabular}{|c|c|c|c|c|c|c|c|c|c|}
\hline $\mathrm{Pt}$ & $\begin{array}{l}\text { Initial Treatment/ } \\
\text { response }\end{array}$ & Muttation & Cytogenetics & $\begin{array}{c}\text { IDH inhibitor } \\
\text { used and dose }\end{array}$ & $\begin{array}{l}\text { Venetoclax dose } \\
\text { and frequency }\end{array}$ & $\begin{array}{l}\text { HMA dose and } \\
\text { frequency }\end{array}$ & $\begin{array}{l}\text { Duration of } \\
\text { response to } \\
\text { combination }\end{array}$ & Toxicity & Response \\
\hline 1 & $\begin{array}{c}7+3 \text { induction therapy/2 } \\
\text { weeks }\end{array}$ & IDH1 IDH2 & Trisomy 13 & $\begin{array}{c}\text { Enasidenib } 100 \\
\text { mg daily }\end{array}$ & $\begin{array}{c}\text { Venetoclax } 400 \\
\text { mg daily }\end{array}$ & $\begin{array}{c}\text { Deciatbine } 20 \mathrm{mg} / \mathrm{m}^{2} \\
10 \text { days once a month }\end{array}$ & $3+$ months & Leukopenia & MLFS \\
\hline 2 & $\begin{array}{l}\text { Decitabine+phase } 1 \\
\text { agent/14 months }\end{array}$ & IDH2 & Normal & $\begin{array}{c}\text { Enasidenib } 100 \\
\text { mg daily }\end{array}$ & $\begin{array}{l}\text { Venetoclax } 200 \\
\text { mg d } 1 \text { to } 14\end{array}$ & $\begin{array}{l}\text { Azacitidine } 75 \mathrm{mg} / \mathrm{m}^{2} \\
\text { for } 5 \text { days } / \mathrm{month}\end{array}$ & $6+$ months & Thrombocytopenia & CRi \\
\hline 3 & $\begin{array}{c}\text { Decitabine } 20 \mathrm{mg} / \mathrm{m}^{2} 5 \\
\text { days a month/enasidenib } \\
100 \mathrm{mg} \text { daily } \times 6 \text { months }\end{array}$ & IDH2 & Normal & $\begin{array}{c}\text { Enasidenib } 100 \\
\text { mg daily }\end{array}$ & $\begin{array}{l}\text { Venetoclax } 200 \\
\text { mg d } 1 \text { to } 14\end{array}$ & None & 2 months & Thrombocytopenia & MLFS \\
\hline
\end{tabular}

remission lasting 14 months and proceeded to additional clinical trials with 8 months of stable disease. At failure of this, single agent enasidenib $100 \mathrm{mg}$ daily was initiated and the patient had stable disease but persistent thrombocytopenic for 10 months. With disease progression, venetoclax $400 \mathrm{mg}$ daily was added and the patient was tolerating well for 20 days but continued to have thrombocytopenia requiring dose reduction to $200 \mathrm{mg}$ daily. Leukocytosis was noted after 1 month (unclear if differentiation syndrome) and azacitidine $75 \mathrm{mg} / \mathrm{m}^{2}$ daily for 5 days monthly was added to the daily enasidenib and venetoclax for 14 days per month maintained at the same dose. A morphologic remission was documented at 3 months and he remains so at 5 months of triplet therapy.

\section{Case 3}

The third patient is 73 years old and received decitabine $20 \mathrm{mg} /$ $\mathrm{m}^{2} 5$ days monthly as single agent for initial AML therapy and with tolerance the enasidenib $100 \mathrm{mg}$ daily was added with cycle 2 and the patient attained CRi at 3 months, though relapsed 9 months after the initiation of the doublet. Venetoclax $200 \mathrm{mg}$ daily was started as he was on posaconazole as well. The patient experienced pancytopenia within 2 weeks and both drugs were held for 1 week. Enasidenib was restarted and then venetoclax $200 \mathrm{mg}$ was added for days 1 to 14 per cycle. Patient has been on the combination for 2 months with MLFS, though transfusion dependent still.

The efficacy of single agent $I D H$ and $B C L-2$ inhibitors has been proven for AML treatment, but this is the first report to our knowledge of their combination. We await the results of the larger phase 1 to 2 combination studies, however current patients in need of alternatives may benefit from this early insight to tolerance. Enasidenib and venetoclax when used together or with a hypomethylator can effectively decrease hematopoiesis even in patients with rapidly increasing leukocytosis. Given the significant cytopenia our initial patients encountered daily $I D H$ inhibition with only 2 weeks of $B C L 2$ inhibition is a reasonable starting point for patients in need.

\section{Conflict of Interests}

Dr. Rizzieri has served as a consultant and receives research support from Agios Pharmaceuticals and Celgene.

\section{References}

1. Short NJ, Rytting ME, Cortes JE. Acute myeloid leukemia. The Lancet. 2018;392(10147):593-606.

2. Lagunas-Rangel FA, Chávez-Valencia V, Gomez-Guijosa MA, CortesPenagos C. Acute Myeloid Leukemia-Genetic alterations and their clinical prognosis. Int J Hematol Oncol Stem Cell Res. 2017;11(4):328-39.

3. Wouters BJ, Delwel R. Epigenetics and approaches to targeted epigenetic therapy in acute myeloid leukemia. Blood. 2016;127(1):42-52.

4. Cruijsen M, Lübbert M, Wijermans P, Huls G. Clinical results of hypomethylating agents in AML treatment. J Clin Med. 2014:4(1):1-17.

5. Saygin C, Carraway HE. Emerging therapies for acute myeloid leukemia. J Hematol Oncol. 2017;10(1):93.

6. Dugan J, Pollyea D. Enasidenib for the treatment of acute myeloid leukemia. Expert Rev Clin Pharmacol. 2018;11(8):755-60.

7. Wei AH, Tiong IS. Midostaurin, enasidenib, CPX-351, gemtuzumab ozagamicin, and venetoclax bring new hope to AML. Blood. 2017;130(23):2469-74

8. Konopleva M, Pollyea DA, Potluri J, Chyla B, Hogdal L, Busman T, et al. Efficay and biological correlates of response in a phase II study of venetoclax monotherpay in patients with acute myelogenous leukemia. Cancer Discov. 2016;6(10):1106-17. 